Childhood and the politics of scale: descaling children's geographies?

Nicola Ansell

Centre for Human Geography

Brunel University

Kingston Lane

Uxbridge

UB8 3PH

Email: Nicola.ansell@brunel.ac.uk

Phone: 01895266085 


\title{
Childhood and the politics of scale: descaling children's geographies?
}

\begin{abstract}
The past decade has witnessed a resurgence of interest in the geographies of children's lives, and particularly in engaging the voices and activities of young people in geographical research. Much this growing body of scholarship is characterised by a very parochial locus of interest - the neighbourhood, playground, shopping mall or journey to school. In this paper I explore some of the roots of children's geographies' preoccupation with the micro-scale and argue that it limits the relevance of research, both politically and to other areas of geography. In order to widen the scope of children's geographies, some scholars have engaged with developments in the theorisation of scale. I present these arguments but also point to their limitations. As an alternative, I propose that the notion of a flat ontology might help overcome some difficulties around scalar thinking, and provide a useful means of conceptualising socio-spatiality in material and non-hierarchical terms. Bringing together flat ontology and work in children's geographies on embodied subjectivity, I argue that it is important to examine the nature and limits of children's spaces of perception and action. While these spaces are not simply 'local', they seldom afford children opportunities to comment on, or intervene in, the events, processes and decisions that shape their own lives. The implications for the substance and method of children's geographies, and for geographical work on scale are considered.
\end{abstract}

Key words: children, scale, flat ontology, culture/nature, materiality, embodiment

\section{I: Introduction}

Over the past decade geographical research relating to children has flourished. Although a minority of geographers had studied children's spatial lives since the 1970s, renewed interest was stimulated by the theoretically innovative 'new social studies of childhood' (NSSC) that came to dominate childhood studies in the 1990s. This new paradigm foregrounded two key ideas: childhood as a social construct and children as social actors. The former provoked geographers to examine socio-spatial differences in the construction of childhood, and the discursive co-construction of childhood and space (for instance, how the home (Holloway 1998) and the rural (Jones 1999) are constructed as spaces of childhood). It is, however, the second notion, that children are social actors, that has most influenced 
geographical research, particularly in the UK.' A wealth of empirical research has detailed how children perceive and engage with the world around them, in diverse geographical settings.

Overwhelmingly, these studies have examined children's micro-geographies: their interactions with and within their immediate environments such as playgrounds (Thomson 2005), living rooms (Wood and Beck 1994), streets (Gough and Franch 2005) and neighbourhoods (Matthews et al 1998). Indeed, children are often viewed as profoundly embedded in their local environments as 'colonisers of small spaces' (Ward 1978) whose 'intimate geographies' (Philo 2000) differentiate them from adults. Children are seen as both learning the world from the body outwards (a built-in assumption of the English primary geography curriculum (Asquith 2006)) and also subject to constraints that 'separate them from a larger and more diverse daily round' (Matthews and Limb 1999:66). More recent scholarship, too, has called for attention to the 'everydayness', and 'minute interactions' (Horton and Kraftl 2006b:75) of children's lives.

The focus on the micro-scale has not gone unnoticed by geographers. Philo (2000:253) urges us that:

'scholarship on the spaces of childhood must focus on more than just the specifics of particular sets of children in particular places, and must do more than just probe the micro-scale, agency-based geographies of childhood behaviour, experience, perception and fantasy ... our scholarship must also look to the larger picture encompassing many different sets of children spread across many different places, and must accept the challenge of tackling the macro-scale, structure-based geographies of childhood as shaped by broad-brush political-economic and social-cultural transformations' (Philo 2000:253)

Relatively few geographers have explicitly examined these wider processes, although many have called for greater attention to them (e.g. Holt and Holloway 2006; Matthews and Limb 1999). Noteworthy exceptions include work that relates changing discursive constructions of childhood to wider social transformations, as both outcome and engine of change (Aitken $200 \mathrm{Ib}$; Crewe and Collins 2006; Gagen 2000; Ruddick 2007); gives attention to the impacts of the restructuring under global neoliberalism of production (Punch 2007; Roberts 1998; Robson 1996; Robson 2000; Tatek Abebe

\footnotetext{
${ }^{1}$ This may be partly attributable to the influence in the late-1990s of the ESRC research programme 'Children 5-16', which focused on children as social actors and incorporated four major geography research projects.
} 
2007) and social reproduction (Cahill 2004; Katz 200I; Katz 2004; Mitchell 2003; Robson 2004;

Ruddick 2003); and explores how socio-economic differences, reflecting broad-scale processes, are reflected in children's material lives (Holt 2006; Pain 2006). This body of work is largely North American in origin and heavily outweighed by numerous micro-geographies of children's everyday encounters.

The local focus of children's geographies is problematic for two key reasons. First, focusing on the parochial sphere and small-scale social action of children leaves unchallenged the processes that affect children across national settings or even worldwide. This is not to equate scale with importance, but to recognise that it is not only locally occurring processes, practices and events that impinge on children's lives. Economic globalisation and neo-liberal policies are transforming life for many young people, but they remain untouched by the small-scale participatory projects that are the focus of much research (Ansell 2005). There are growing calls for policy relevance (Matthews 2005; McNeish and Gill 2006; Smith 2004): both direct applicability to policy and practice, and contribution to wider political debate. This implies engagement not only with child-focused policy, but also with broader political processes that impinge on children's lives and from which, in the UK at least, child policy is increasingly removed (McNeish and Gill 2006). Secondly, the localism of children's geographies is a concern because, while research deals predominantly in empirical studies of the everyday lives of children, and not the wider processes, discourses and institutions to which these connect, children's geographies are not seen as relevant by other geographers. As Aitken (200 l b: I 23) points out: 'the places and practices of children's everyday life are rarely considered a dynamic context for understanding social and material transformations'. While we should not simply accept the 'denigration of the local as small and relatively powerless' (Gibson-Graham 2002:27), it is undeniable that, much as those deemed local are often marginalized, so too are studies of the local.

The purpose of this paper is to explore why children's geographies have so strongly emphasised the local and, by engaging with developments in scale theory, to examine how this parochialism might be overcome. I begin, therefore, by suggesting three reasons for the localism of children's geographies. I go on to consider scale theory, and some ways in which children's geographers have employed and adapted scalar concepts in order to move beyond the parochial. Finding these somewhat unsatisfactory, I propose that the notion of a flat ontology might offer a way to overcome some difficulties around scalar thinking, and provide a useful way of conceptualising socio-spatiality in 
material and non-hierarchical terms. Bringing together flat ontology and work in children's geographies on embodied subjectivity, I examine the nature and limits of children's spaces of perception and action. Finally, the implications for the substance and method of children's geographies, and for geographical work on scale are considered.

\section{II: Explaining the localism of children's geographies}

The fact that children's geographies tend to focus on the local is not accidental, but related to three broad factors: the early traditions of children's geographies; widespread contemporary attitudes towards children, particularly in Western societies; and choice of social theory. These are explored below.

The early interest of geographers in children's lives (Blaut and Stea 1974; Bunge 1977; Hart 1979) focused on children's environmental perceptions and experiences (though not to the exclusion of wider social processes). In challenging the rigid developmentalist views of Piaget (1972) that then dominated social scientific research on children, these geographers drew on the ideas of other developmental psychologists such as Vygotsky (1933/1967) who saw the immediate environment as an important resource for children's cognitive and social development. Child development, they surmised, was not a universally predictable process, but depended on the context of childrearing and thus a host of socio-economic factors.

Geographers employed developmentalist ideas most explicitly to examine how children's engagement with their environment expands over time. Matthews and Limb (1999:75) relate, among other similar models, that of Erikson:

'Erikson postulates that environmental mastery comes about through a continuing relationship between the child and three successive scales of environmental contact: the autosphere, the microsphere and the macrosphere. The autosphere is the child's first environment. It begins and centres on one's own body ... With time, so the child's map of the world extends to incorporate familiar objects and persons ... The macrosphere is the world shared with others'

Children's 'home range' was mapped, and modelled as series of concentric circles, seemingly affirming linear development over time. In such models, 'The routine world of a six-year-old is no more than a 
'spatial bubble' within the world of a young teenager' (Matthews and Limb 1999:72). Research, such as that by Katz (199I; 1993; 1994; 1998), has uncovered significant differences culturally and historically as well as by class, ethnicity, gender and sibling order in the pace and consistency of home range expansion. Indeed, it is increasingly recognised that many children's lives are more fragmented and transitory than an expanding home range model would imply, and that even where young children's independent range fits such a pattern, their dependent mobility generally maps onto that of adults (Tillberg Mattsson 2002). However, despite the growing sophistication of home range studies, their effect is often to focus attention on children's engagement with the environment within their personal range, rather than the (external) processes shaping that range and experiences within it.

The idea that young children live spatially confined lives is not simply an artefact of the way in which they are studied, however. In dominant Western discourse children belong within families, homes and private space (Holloway and Valentine 2000a). Since the nineteenth century, children have progressively been confined to special spaces of childhood (schools, playgrounds) (Aries I962). In parallel, children's access to the public sphere has diminished (Qvortrup 2005). Children's claims on societal resources were to be exercised principally through the family, an expectation that served to depoliticise childhood. This privatisation and confinement continues today with welfare reforms that 'push responsibility down' to the level of families (Boyer 2006:35), declining investment in safe public space for children's recreation (Katz 2004), and discourses of fear and appropriate parenting that confine children within the home and institutional or commercial childhood spaces (McKendrick et al 2000; Valentine 1997a; Valentine 1997b). Even where children's presence in public space persists, for instance on working class estates (Skelton 2000) and in Third World cities (Beazley 2000; Young 2004b), they are commonly seen as illegitimate occupiers of adult environments.

It is important not to underestimate children's spatial mobility, and there is a growing body of work on children's migration (Dobson and Stillwell 2000; Sporton et al 2006; van Blerk and Ansell 2006a; van Blerk and Ansell 2006b; Young 2004a), if much less on other forms of travel beyond their immediate environments. Nonetheless, children's direct experience of the world is often spatially restricted. Given that research with children has focused largely on that experience, it is unsurprising that it emphasises the local scale. 
Geographical research about children need not, of course, focus on their direct experience of the world. That it continues to do so reflects the influence since the early 1990s of the "new social studies of childhood' (NSSC). Axiomatic to this approach is the assertion that children are social actors, engaging with the world around them. This has prescribed not only the subject matter of research (children's engagements with the world), but also the methodological approach. Children-centred research methods are advocated, which treat children as competent informants and seek to understand the world from their perspectives. This is regarded not simply as an effective way of uncovering children's lives, but also an ethical imperative. At a time when social constructivist social science was decentring the subject, NSSC was preoccupied with recovering children's agency, rendering any questioning of children's autonomous subjecthood potentially heretical (Prout 2005). Under the new methodological orthodoxy, the 'child as sage' (McNeish and Gill 2006:5) is assisted to reveal what they know of the world through research tools aimed at eliciting or supplementing their verbal accounts. Visual methods such as drawing and photography are popular but tend to focus attention - of children and researchers - on the proximate material environment, leaving relations with unobserved places unexplored (Ansell and van Blerk 2005). Often participatory methods are adopted, as these are deemed to maximise children's agency in the research process. Yet it is increasingly recognised that in '[f]orefronting contextualized knowledge and personal experiences, participatory research and practice has necessarily placed an emphasis upon the local, often failing to theorize connections to broader social processes' (Cahill and Hart 2006:ii).

Recently NSSC has been subjected to critique. Alan Prout (2005) argues it was inserted into modernist sociology where, alongside celebrating children's subjectivity, it incorporated the dualisms of Enlightenment thought: child/adult, local/global, concrete/abstract, agency/structure. Some geographers have attempted to reconcile or undermine dualistic thinking: for instance Holloway and Valentine (2000b) in their critique of Theorising childhood (James et al 1998), or Katz' (2004) interweaving of descriptions of children's everyday lives with political-economic analysis of globalisation in Growing up global. Nonetheless, work within the NSSC paradigm has predominantly emphasised agency over structure, concrete over abstract and local over global. In most 'childrencentred' studies, structural processes and abstract themes (for instance, 'social justice'), on which young children cannot speak directly, are generally neglected. 
Too often local, concrete and agency are conflated into an acceptable focus for research, in opposition to a global, abstract or structuralist perspective that is viewed with suspicion as too 'distant' from real children. Significantly for this paper, although Aitken (2004:580) advises: 'Interpretive lenses that focus simultaneously on local and global representations and lived experiences enable a more comprehensive analysis', this is seldom attempted. While the local is admired as the scale of experience and the everyday, any notion of a 'global' or 'universal' child is condemned as a 'sterile concept' (Matthews and Limb 1999) or 'hollow category' (Aitken 200 Ib:I22). Global discourses of childhood are considered 'dangerous' (Pain 2004) because they presume a false commonality of experience. It is certainly true that worldwide there are 'vastly different understandings of what it is to be young' (Ruddick 2003:357), and the export of policies and practices that assume universal experience, or aspire to globalise a middle-class Western ideal of childhood, has had problematic consequences (Aitken et al 2006). The deconstruction of such discursive manoeuvres is valuable. However, there is also a need for more research that seeks to uncover the globally widespread impacts of many aspects of globalisation (as, for instance, that undertaken by Katz (2004), Mitchell (2003), Roberts (1998) and Ruddick (2003)) rather than retreating from global to local.

Although NSSC still dominates children's geographies, in recent years, some geographers have stepped outside this paradigm and begun to engage with children's embodiment, emotional geographies and with non-representational theory (e.g. Horton and Kraftl 2006b; Jones 2005; Philo 2003). Even these studies, however, remain concerned with intimate geographies - the everyday, minute, 'closest in'. The notion that "spaces' are encountered in and through embodiment, in and through practices, in and through particularly located everyday lives' (Horton and Kraftl 2006b:85) reinforces concern with the concrete and local and with children's everyday experiences. Broadly, this work celebrates the 'local' side of the dualisms: body and emotion over mind and reason. However, I will return to it in section IV to explore how it might help shed light on children's wider geographies.

\section{III: Scale theory and children's geographies}

While most research in children's geographies is focused on the local, a number of scholars have explicitly employed conceptualisations of scale in order to make sense of children's lives and their relationship to wider processes. Jennings et al (2006), for instance, show how children's work is understood very differently when examined at household, community, state or global scales. In so doing, they approach scales as relational, yet pre-existing, levels inscribing different sets of social 
processes. Roberts (1998:4), by contrast, shows how children's work stretches across scales 'as the hands of child workers touch (make produce) the products touched (eaten, used, played with, consumed) by other children and adults half a world away'. These are but two ways of employing scalar framings, and reveal some of the ambiguities of scale theory.

Geographical interest in scale has expanded dramatically since the 1980s, as political and economic geographers have sought to understand heightened levels of global interdependency. At stake for many was a political challenge: how might 'locally situated' political actors achieve change in relation to 'large-scale' economic transformations (Cox 1998b; Swyngedouw 1997). Feminist economic geographers have dislodged scale theory from its focus on capitalist production to illuminate the scalar relations of social reproduction and consumption (Marston 2000). While the principal interest has been on the global-local nexus, there is growing recognition of more intimate scales of home and body, and the importance of culture and emotion (Blunt 1999; Marston 2000).

Critical consideration of the concept can be traced to the work of Taylor (1982) who, in developing his 'political economy of scale', recognised that scale is not a natural phenomenon that pre-exists society. Theoretically, most scale analysis is founded on Lefebvre's conceptualisation of the dialectical production of space and society (Collinge 2005). It is now broadly accepted that scale is not a 'preordained hierarchical framework for ordering the world' (Marston 2000:220), but rather is socially constructed. This can be seen in relation, for instance, to the 'national scale' which is clearly a product of particular historical circumstances. However, while scales are not ontologically preordained, this need not imply scale has no material existence. For Cox (1998a:43-44), for example, 'Like space ... scale is constituted by, but is not reducible to, objects'.

While there are others (Jones 1998; Marston et al 2005) who dispute scale's ontological status, scales are certainly used epistemologically, as 'mental devices for ordering the world' (Herod and Wright 2002:5). This ordering may take place through metaphors, perhaps the most common being a set of Russian Matryoshka dolls wherein 'each constituent doll and each constituent scale is separate and distinct and can be considered on its own, but the piece as a whole is only complete with each doll/scale nesting together, such that the dolls and scales fit together in one and only one way' (Herod and Wright 2002:7). Although this model is adopted in many formal organisational diagrams, and affects the enactment of political and social relations, its implication that scales correspond to fixed, 
clearly defined, bounded areal units fails to describe or explain how scales are constructed and experienced.

Apart from these pictorial metaphors, Howitt (2002) has categorised approaches to scale in terms of three facets: size, level and relation. Understanding scale as size (sometimes termed horizontal scale) relates to spatial extent: the global is larger than the local and contains many locals. Scale as level (or vertical scale) relates to the level at which processes operate, each scale in a nested hierarchy subsuming the layers below (local subsidiary to national subsidiary to global). Scale as relation encompasses size and level, but focuses on the relationship between smaller and larger scales. While any scale only exists in relation to other scales, larger scale entities do not simply contain smaller scale entities, but 'larger scale entities are at the same time contained within smaller scale entities' (Howitt 2002:305).

There have been three key developments in thinking about scale that potentially challenge the microscale focus of children's geographies: first, a shift from viewing scale in terms of hierarchically arranged bounded areal units towards a network metaphor in which scales interpenetrate; second, related attempts to destabilise the dualistic association of local and global with concrete and abstract or agency and structure; and third, recent calls to abandon the concept of scale entirely and replace it with a 'flat' ontology. The first two have already influenced research in children's geographies, as outlined below. The potential of the third is explored in later sections of this paper.

\section{I: A network concept of scale}

As suggested above, to think of scales as self-contained territorial units is unhelpful. Massey (1993:155) argues that instead of bounded territories, 'we need to conceptualize space as constructed out of interrelations, as the simultaneous coexistence of social interrelations and interactions at all spatial scales, from the most local level to the most global'. Any point in space is a node in a network of relationships, impacted by and impacting on events both near and far. These 'networks span space rather than covering it, transgressing the boundaries that separate and define ... political entities' (Marston et al 2005:4I7). Local and global interpenetrate such that all places are simultaneously both local and global. 
Using a network conceptualisation of scale, some geographers have sought to demonstrate that children's lives are not simply local. Holloway and Valentine (2000b) found British children used the internet to find pictures of actresses, pop stars and supermodels, all 'part of a broader global youth culture'; but did so 'within 'local' cultures of computing' (p. 769). In researching children's 'lived experience', they demonstrated that 'children's worlds of meaning are at one and the same time global and local, made through 'local' cultures which are in part shaped by their interconnections with the wider world' (Holloway and Valentine 2000b:769). Aspects of this 'wider world' that do not appear on the children's computer screens, however, remain unexamined.

In exploring how Mayan young people incorporate global youth culture in particular local ways, Massey (1998) gives greater attention to global unevenness in encounters with globalisation. A Mayan wristband worn by a Californian youth and an American t-shirt worn by a Guatemalan teenager are not symmetrical in the power relations they inscribe. Similarly, Katz uses the idea of 'countertopographies' to draw connections between the lives of children living in the Sudanese village of Howa and in New York, in order 'to grapple with the myriad ways global capitalism and other large-scale processes ricochet through and between disparate places' (Katz 2004:259). She shows how 'development' in Sudan and disinvestment from public space in New York both have disintegrative effects on the environments young people inhabit, and in turn on young people themselves, and are both products of the same global neoliberal economic restructuring. Furthermore, geographers have considered how young people do not merely respond to global processes in local places in particular ways, but 'live' global identities in local ways, such that "the global' constitutes a space which is 'brought to life' ... in and through the embodied performances of social actors' (Horschelmann and Schafer 2005:224). Thus we are beginning to recognise not only 'the local as the product of the global [but also] the counterpoint to this: the local construction of the global' (Massey 2005:I0I). It is worth noting, however, that, with the exception of Katz's work, most research on lived experiences of globalisation focuses on older youth who, owing to their participation in 'global youth culture', are, in contrast to children, often regarded as more global than adults (Massey 1998).

While a network conceptualisation of scale captures significant interrelations, there is a risk of imagining a space of unconstrained flows of connectivity (Jones et al 2007), which fails to recognise the constraints children face. It is also important to recognise that (partially) bounded spaces are still encountered on the ground (Paasi 2004), particularly, perhaps, by children. 


\section{2: Dissociating global/local from abstract/concrete}

A second preoccupation of scale analysts has been the dualistic relationship between local and global and its conflation with concrete and abstract. Gibson-Graham (2002:27) describes it thus: 'Globalism is synonymous with abstract space, the frictionless movement of money and commodities, the expansiveness and inventiveness of capitalism and the market. But its Other, localism, is coded as place, community, defensiveness, bounded identity, in situ labor, noncapitalism, the traditional'. This 'equation of the local scale with contextual particularity' (Brenner 2001:602) has been critiqued, perhaps most notably by Massey (2005:184) who argues that ' $[t]$ he couplets local/global and place/space do not map on to that of concrete/abstract. The global is just as concrete as is the local place'.

Holloway and Valentine (2000b) used Massey's idea of a 'progressive sense of place' to critique the way in which James et al's (1998) landmark NSSC text schematically represents studies of childhood in relation to a global/local binary, mapping directly onto universal/particular. In their research into children's use of the internet, they seek to destabilise these dualisms. Like many researchers, they do so by focusing on the particularity of the global, with minimal discussion of the abstract, universal or structural. Rather than seek out abstract processes/ structures that affect children's lives, they explore children's concrete relations with 'wider society'. Children's relations to distant places through use of the internet are shown to be merely an aspect of everyday life, little different from their relationship with events within the home or school.

The idea that local/global, concrete/abstract, agency/structure can be disconnected in this way is, however problematic. While some research has demonstrated that children can relate to distant ('global') places in concrete ways, most studies of globalisation and childhood adopt an abstract, often structuralist approach (e.g. Roberts 1998; Ruddick 2003). Even Katz' 'countertopographies' largely juxtapose concrete (local) outcomes with abstract (global) causes. Marston et al (2005) developed what they describe as a 'flat' ontology, rejecting entirely the concept of scale, in part because they consider it impossible to retain a local/global distinction that is not firmly tied to other binaries. They note: 
'the difficulty if not the impossibility of disentangling scalar hierarchies from ... the micromacro distinction in social analysis ... Nor are local and global easily separated from agency and structure, in which subjectively experienced and individually felt thoughts, feelings and actions are held opposed to and to be integrated with objective, broadly operating social forces, relations and processes ... there seem to be no end of examples in which economic macro-isms are articulated alongside their attendant 'global spaces', while (minor? reproductive?) social practices are cordoned off in their respective localities (or even homes)' $(\mathrm{p} .42 \mathrm{l})$

\section{3: Flattening space?}

This raises the question of whether a flat ontology might be useful in reconnecting children's geographies with extra-local processes beyond direct concrete relationships. Marston et al's (2005) critique of scale rests on the difficulty of maintaining a distinction between scale as size and as level, thereby rendering any (albeit horizontal) conception of scale hierarchical; the difficulty of disentangling scalar hierarchies from the micro-macro distinction; the tendency for researchers to take scale as a conceptual given, on which to construct explanations; and the paradox of undertaking self-reflexive, situated, 'global' research. The alternative they propose is 'materialist but poststructuralist and nondialectical' (Jones et al 2007:264), and accounts for socio-spatiality through Schatzki's notion of a social site, defined as 'the context, or wider expanse of phenomena, in and as part of which humans coexist' (Schatzki 2002:146-7, cited in Marston et al 2005:425). This requires no “outside over there' that, in turn, hails a 'higher' spatial category' and no 'prior, static conceptual categories' but gives 'sustained attention to the intimate and divergent relations between bodies, objects, orders and spaces' (Marston et al 2005:424-425).

The idea of a 'human geography without scale' has attracted numerous objections. Among the more persuasive is that, as an organising principle of actually existing political and economic systems, scale does have material impacts, albeit not totally constraining, and these bear scrutiny (Hoefle 2006; Mahon 2006). Secondly, 'scalar concepts are fundamental to the organization and presentation of human-geographical narrative' (Jonas 2006:399). Having long operated with a worldview that treats scale as commonsense, we cannot meaningfully engage with existing scholarship unaware of the impacts and limitations posed by a scalar imaginary. I am not advocating in this paper an excision of scale from geography, but suggest that flat ontology offers some useful insights for children's 
geographies. Particularly valuable are the focus on the materiality of socio-spatiality, and on avoiding the transcendental and abstract associations of the global that make it hard to study on the same empirical plain as children's everyday lives.

While Marston et al draw principally on Schatzki and Deleuze, they also acknowledge a debt to Latour's actor-network theory which also proposes a flat ontology and offers a clearer recipe for the uncoupling of global/abstract from local/concrete. Contra Massey, Latour (2005) conflates 'structure' with 'global' and 'interaction' with 'local', but seeks to destabilise the opposition between these two pairings. He is critical of the term 'social' being used 'to designate two entirely different types of phenomena [sic]: one of them is the local, face-to-face, naked, unequipped, and dynamic interactions; and the other is a sort of specific force that is supposed to explain why those same temporary faceto-face interactions could become far-reaching and durable' (Latour 2005:65), and suggests that social sciences have become caught in 'a painful oscillation between two opposite poles, one more structural and the other more pragmatic' (Latour 2005:168). Rather than reduce the global to another form of interaction, however, he seeks to undermine both poles.

Unlike the geographers cited above, Latour does not simply see both local and global as indistinguishably concrete. Rather, he argues that 'the notion of a local interaction has just as little reality as global structure' (Latour 2005:203): 'if 'structure' is an abstraction, so is interaction! If one is more real and concrete, so is the other' (Latour 2005:168). This view of local interaction is based on the premise that 'Action is not done under the full control of consciousness' (Latour 2005:44). Latour contrasts 'the hidden action of some invisible structure - at which point, nobody in particular was doing any action' with an equally improbably view of fully centred and self-aware individual human actors (Latour 2005:205-206).

There is, then, no a priori distinction between global and local, although some places are more connected to other places and some connections become more durable (Latour 2005). These connections do not flow across a frictionless plain (Marston et al 2005), and I argue below that the frictions of distance and of entrenched practices shape children's engagement with the world.

My reason for bringing flat ontology and actor-network theory into association with children's geographies is not a belief that they represent unproblematic social theory for framing research in this 
field, but because they might point to ways of addressing the difficulties children's geographers have had in looking beyond children's immediate environments to things that affect children's lives; difficulties that have not been fully resolved by the engagements with scale theory discussed above. The idea is to employ them to investigate whether and how children's geographies might be explored differently. Moreover, their application to the lives of children might raise new questions for geographical theorisations of scale.

\section{IV: A child-centred material spatial ontology}

This section begins tentatively to investigate what happens to the scaling of children's geographies if children are seen as nodes of material connections to places near and far - nodes that are embodied, perceiving, acting, expressing, connected with other humans and with objects, both natural and social beings, but not fully-aware autonomous agents. To do so it draws on a growing body of work in children's geographies that, in reconsidering subjectivities, stresses the significance embodiment and the limits to individualised agency.

Many geographers have, over the past decade, developed an interest in the 'messy, fleshy' (Katz 200I) embodied aspects of social existence. Children's geographers are increasingly conscious that embodiment is fundamental to being in the world (Colls 2007; Horton and Kraftl 2006a; Horton and Kraftl 2006b). A focus on children's bodies as key sites for identity construction (Gagen 2000; Valentine 2000) has given way to consideration of how embodiments are produced through everyday practices (Holt 2004). Children are simultaneously cultural and natural beings (Prout 2005), and their bodies are much more than signifiers of identity positions. The social, psychological and physiological are fundamentally connected, for instance in eating disorders (Evans 2004), yet the materiality of bodies remains underresearched (Colls 2007; Harker 2005).

While actor-network theory suggests symmetry between human bodies and inanimate objects, this downplays human capacity for feeling (Schwanen 2007) and intentionality (Miettinen 2000). I largely concur with Grosz (1994:xi): 'If bodies are objects or things, they are like no others, for they are the centres of perspective ...'. Bodies observe and act in the world through multiple senses, and are thereby 'open to the world' (Horton and Kraftl 2006b:78). '[F]eelings, sensations and modes of experiencing ... are continually productive ... of subjectification' (Harrison 2000:5 I4). That subjects are constituted relationally through embodied being, rather than cognitive consciousness, has long 
been recognised by those seeking to shape personhood in the young. The nineteenth century Cornish Methodist church viewed children's bodies as sites of moral performance and thus emphasised bodily discipline (Bailey et al 2007), while early twentieth century American 'physical education theory constructed the development of child consciousness as a ... muscular process' (Gagen 2004:4I7).

The challenge this account of embodied subjectivity poses to the liberal concept of agency that infuses the NSSC is increasingly recognised. Some children's geographers have begun to view agency as performative rather than innate (Kesby et al 2006), as relational and becoming rather than individual and fixed (Holt 2006). Drawing on longstanding feminist critiques of the autonomous liberal subject acting 'under the full control of consciousness', Ruddick (2007:5 I4) argues, 'the child is a limit to the liberal subject: it is, de jure, an impossible subject since, by liberal definition, the child cannot speak for him or herself without adult authorization'.

Much of what has been written by geographers about children's embodiment has focused on the micro-scale. However, through the senses children's bodies are 'open to the world' (Horton and Kraftl 2006b:78) beyond the proximate. Children perceive and connect with and through space as natural/cultural beings. Their connections do not freely span space, but are limited by physical/social constraints. In line with McCarthy's (2005:736) assertion that scale is 'produced simultaneously by social processes and by biophysical processes that elude human control', the following sections explore the (de)scaling of children's spaces of perception and action.

\section{I. (De)scaling perceptual space: intimacy and distance}

In exploring the 'geography closest in', geographers increasingly recognise that sensory experience is fundamental to engagement with space (Harrison 2000). Our senses and sensations, perceptual and kinaesthetic, enable, but pose physical limitations on, our encounters with the world: taste and touch require immediate proximity; sight and hearing allow access to perceptual information from somewhat further afield, although barriers intervene, and resolution declines with distance. Biophysical processes connect us to our most proximate environments in more visceral, intimate ways than to more distant places. That which is perceived through touch or taste is known more intimately than that which is merely smelt, seen or heard. ${ }^{2}$ However, 'The problem with 'the

2 Bingley (2003) argues that visual perception can be 'distancing' from physical contact with surroundings, and
move an individual into a predominantly 'cerebralised' awareness' (p.334), although sensory experience is 
geography closest in' metaphor is that it suggests an expansion of self-awareness in a relatively limited linear progression away from the body ... a problematic metaphor of reaching out from the self to a series of different spatial scales' (Aitken 200la:65). However, children's engagement with space is neither purely biophysical nor individualised.

Children always engage with space as simultaneously natural and social beings. Aitken draws on Winnicott's object relations theory to understand the sociality of their earliest encounters with the world. For Winnicott, object relations refer to 'both the conscious and unconscious relations that people have with places, environments and other people' (Aitken $200 \mathrm{la}$ : III). Children never exist apart from the objects that surround them. Newborn infants have no conception of themselves as bounded, distanced or alienated from their environment. Their senses introduce them to a fundamentally social world; their earliest perceptual space may be their caregiver. Gradually a space of 'transition', comprising objects (bunnies, security blankets) with which they form highly charged affective relationships, allows them to recognise themselves as distinct from the external world, and from this they first enter into social and cultural practices (Aitken and Herman 1997).

Embodied encounters then, are not simply perceptual, but always involve emotional, cognitive and imaginative engagement; they are always relational. Other than, perhaps, in the youngest infants, perception cannot take place without interpretation, and interpretation involves bringing into play memories, images and feelings acquired elsewhere. Thus affective experiences of place are neither individualised nor unmediated. '[W]e are always in the process of 'making sense' of the world' (Bingley 2003:333). Children's experiences of their environments may be more immediate than those of adults, insofar as they do not have such extensive or elaborate social or cultural lenses through which to interpret them, but they are never 'raw perception'.

\section{Children's embodied relations with the world are both biophysical and social, but this} biophysical/social coupling is not simply 'local'. Every encounter of a child with her/his environment encompasses far more than immediate surroundings. The familiar objects in a room derive (in multiple ways) from distant places (Wood and Beck 1994). 'Face-to-face' relations always involve relations in

continuous, with 'numerous cross-overs and interactions between senses' (p.333). This 'tyranny of the visual' is characteristic of Western societies (Bunkse 2007). It may be that for young children other senses than the visual are more dominant, relative to adult experience - Bingley suggests that 'the tactile is the primal sense' (p.334), but 'earth-bound senses' (smell, touch and taste) are less readily articulated than 'sky-bound senses' (sight and hearing) (Bunkse 2007). 
other places, most of which escape children's conscious awareness. A child's home reflects class and culture (Aitken and Herman 1997:80). While space may appear neutral and contained, it is actually shaped by interrelations that extend beyond any immediate interaction between the child and what s/he perceives. Equally a (very internal) sense of hunger may evoke associations, but not full awareness of its cause(s), however 'concrete' these may be. The world with which children interact is the product of events, policies, discourses and decisions with diverse origins in time and space. Sensory perceptions thus provide children with very incomplete descriptions of the world they encounter.

While children's 'immediate' encounters contain intrusions from further afield, children's perceptual space is rarely confined to the proximate. Holidays or migration may take them further afield. While their direct perception is constrained insofar as their ability to move through (physical and social) space is constrained, 'television and other media bring [the] 'outside' to children' (Aitken and Herman 1997:8I). Telephone, internet, photographs and video mean that friends and relatives who have travelled beyond the range of direct perception can be heard or seen in indirect ways. Equally, artefacts (products, clothes, food, toys) are brought within perceptual range from places near and far. These may carry traces of people and places: a soft toy from home can be 'a means for letting the child experience an absent familiarity in the nursery through touch' (Schwanen 2007:18).

Perception of distant people and places relies on technologies - transport of individuals, or technologies that move information and artefacts to within the field of perception. Such technologies may be less available to children (particularly young children) than to adults (notwithstanding many children's facility with the internet). While they allow personal relationships to be maintained across space, and knowledge to be gained of distant places, they do so through the less intimate senses of sight and hearing, and requiring greater levels of interpretation than face-to-face contact. Children (very young children in particular) may therefore encounter distant places and people less intimately than adults. Nonetheless, drawing a line around their lived reality (Massey 2005) is not an option.

While there is clearly no simple linear relationship between intimacy and distance in children's relations with the world, and no clear-cut boundary between the 'scale' of direct experience and that which lies beyond, there is a qualitative difference between how children perceive and relate to the environment of their home or garden and that which they view on television. The different senses 
offer different levels of intimacy, even within the realm of 'direct experience'. Fleeting perceptions are arguably of a different order from prolonged or repeated contact. Places glimpsed through a car window are perhaps experienced less 'directly' than those watched daily on television.

An understanding of scale that rests on material relations requires a qualitative (but not dualistic) distinction between relations that are near or far. Near and far are defined in terms of distance, but distance does not conform to Euclidean geometric rules. 'Viewed topologically, time-space consists of multiple pleats of relations stitched together, such that nearness and distance as measured in absolute space are not in themselves important' (Latham 2002). Distance is produced and regulated in part through technology, but it is also affective, discursive, imaginative and symbolic.

Children, then, encounter near and distant places in multiple conscious and unconscious ways. While their most intense interactions may be with proximate spaces, the world they encounter is produced through diverse interactions and they constantly engage with things that connect with distant places books, school curricula, fruit or clothes produced elsewhere. Massey (2005:185) cites David Harvey (1993): 'the multiple and mediated relations which constitute [modern] society across space and time are just as important and 'authentic' as unmediated face-to-face relations'. This may be so (although, as has been shown, face-to-face relations are not unmediated), but face-to-face relations are qualitatively different in ways that, arguably, matter to children. Furthermore, while children's experience of the world is not 'local', only a fragment of this experience can be captured by talking to children. The implications for the substance and method of children's geographies will be considered in section $\mathrm{V}$.

\section{2. (De)scaling action space}

Children not only perceive and interpret the world, but also act upon it, with varying degrees of intent. Indeed, the world is constructed in part through children's actions. These actions together inform how society (adult and child; individually and collectively) understands and responds to children. In this way, children infiltrate many spaces from which they remain physically absent and often unaware. While most actions of children simply contribute to the ongoingness of the world, some are intended to resist or transform. Also, some, whether intentionally or not, are more farreaching than others. 
Horton and Kraftl (2006b:87) point out that 'everything is always done through or with our bodies'. If our actions are confined to where our bodies can reach, they are even more tightly confined than our perceptual range. In practice, of course, the effects may extend further, following multiple pathways of interconnections. Furthermore, things are not done through bodies alone, we also deliberately employ technologies (constituted materially and socially) that allow action (albeit indeterminate and not under fully conscious control) at a distance - telephone, internet, postal service and so on. As Schwanen (2007:12) highlights, 'globalization and technological advances have increased opportunities for action at a distance and reconfigured the meaning of the words near and far.' Importantly, adults have more ready access than children to these technologies and to the forms of social and political organisation that support action at a distance.

Viewing children as nodes in networks emphasises that they do not live in contained 'bubbles', but interact with people and places near and far. Children may be less densely connected than adults. Furthermore, interactions do not all take the same form or connect in the same way. From a network perspective, 'Sites ... differ ... in the direction of the movements to and fro as well as in the nature ... of what is being transported: information, traces, goods, plans, formats, templates, linkages, and so on' (Latour 2005:204-205). Purposeful actions connect in different ways from inadvertent actions, and actions do not directly map perceptions. Children are arguably much more (deliberately) acted upon from a distance than they are able to (deliberately) act on others (people or institutions) at a distance. Whereas porous boundaries may allow the ingress of 'curriculum guidelines, teaching materials, letters laying down funding policy and so on' (Prout 2005:82) into schools, for instance, children cannot readily send missives in the other direction. The comments of Dirlik (1999:42, cited in GibsonGraham 2002:34) in relation to international differences are apt:

'What appears today as something of an exchange, in which both sides participate, may turn out to be less of an exchange because it is unequal exchange, because one side will see its life transformed by television while the other side will through the same television invade the world.'

Children may be able to act within and transform their perceptual space - even toddlers can transform playroom space (Gallacher 2005). However, children's lives are greatly affected by decisions, events and activities that take place at some remove from their own perceptual fields, in, 
for instance, national and international policy-making arenas. These they have limited capacity intentionally to influence, although such events reflect discourses of childhood in whose construction children are (generally unwittingly) implicated.

On occasions children are transported into (or closer to) decision-making arenas. Significantly, consultation with young people is commonest at 'local' level (Hart 1997; Matthews et al 1999). Yet policies and practices enacted locally affect children no more than those determined in national or global fora. While children may encounter the world most intensely in their immediate surroundings, the processes that shape the world they experience are no more products of local decision-making than is true for adults. Furthermore, 'it cannot be assumed that experience of politics at a local level inducts young people into involvement in politics more generally' (O'Toole 2003:88).

Where groups in society are 'marginalised' because key events that affect them are enacted in spaces removed from those they physically inhabit, political geographers suggest they should 'jump scales' (Featherstone 2003:408), or constitute scale through their actions in a way that allows them to exercise influence (Herod and Wright 2002:II). This might imply, for instance, internet-based international activist networks lobbying international financial institutions. However, 'Not all actors can create desired scales given restrictions from more powerful actors, networks and scales, not to mention economic, social and political processes, and rescaling might not be possible' (North 2005:224). For children, scale jumping is seldom a realistic strategy to transform the conditions of their lives. Children lack access to important knowledge about their own lives, and are precluded, in part by the deployment of scalar strategies (containment in schools and other micro-spaces of childhood), from capacities to know or act in public (decision-making) spheres. Defining children as belonging inside, as inherently 'local' beings diminishes their capacity to act in relation to policies and practices that impinge on their lives. These are 'forces beyond the control of individual children' (Holloway and Valentine 2000a:6), not because they are abstract structures that impose a determining influence, but because they take place in spaces to which children have no right or means of access.

Children may be given access to decision-making arenas where 'child policy' is at issue. As Ruddick (2007:5 I5) points out: 'children are 'heard' most clearly in accepted roles - consulted in designing their own leisure spaces, parks and playgrounds, spaces where their voice is not complicated by its relationship to 'others". Furthermore, physical presence goes only a small way towards enabling 
children to contribute meaningfully, given their limited contextual knowledge and lack of control over the outcomes. Equally, objects such as reports, posters or video may be deployed to convey children's voices (see, for instance, van Blerk and Ansell 2007). This certainly does not constitute autonomous agency, and inevitably much information is lost. While such 'artefacts ... enable humans to act incorporeally at a distance through delegation' (Schwanen 2007:19), the outcomes are highly indeterminate, with intentions deliberately or inadvertently distorted. However, in neither case do children exercise no agency.

In sum, children interact with people and environments in diverse ways - they perceive and interpret the world around them; are affected by and act upon the world, with varying degrees of consciousness and intent. All of these interactions take place both 'locally' and over varying distances. Relationships with people and places in close proximity are arguably qualitatively different from those enacted at a distance for both adults and children. However, children in particular may have a special relationship with the people and places immediately around them, because they lack such ready access to the technologies, interpretive repertoires or social status that would allow equivalent relations at a distance. While children are social actors, they do not act as autonomous individuals and are inherently very limited in how far they can deliberately change their world(s).

\section{V: Implications for children's geographies}

A scale analysis of children's geographies should not only provoke us to 'subvert scale relations that assault the lives of young people' or to understand how scale is 'negotiated and restructured to suit and/or constrain young people' (Aitken 200 la:24). We also need to recognise how the scaling of children's geographies constrains research with children and how this scaling can be subverted, to support research that is not just more policy relevant but able to contribute positively to transforming the world(s) children experience. This may suggest new directions in both thematic focus and methodological approach.

If children's relationships with the people and places in close proximity are especially intense, and their capacity to effect deliberate change is highly constrained, far from encouraging research focused only at the micro-level, it becomes much more important to research beyond this. While there is no reason to abandon explorations of children's direct experiences of the world, research is needed that recognises that experiences involve multi-sensory engagement, and that sensory experience is not 
readily reflected upon verbally (Bingley 2003:330). Visual methods may be tempting (visual perception being more readily articulated), but these, too, only tap into limited aspects of spatial experience. Research might also fruitfully explore children's use of technologies to engage with more distant people and places, through travel or communication, and also how they interpret what they perceive - the discourses and emotions that shape and give meaning to their perceptions, and the sources of these.

If research into children's geographies is to be relevant to the transformation of children's lives, however, it is crucial to consider not only children's encounters with the world, but also the processes, decisions and events that shape the world they perceive, interpret and act upon. This need not imply a structuralist approach. Indeed, a flat ontological approach requires more than recourse to 'structures' to explain how children's lives are shaped by events at a distance. If society is understood in terms of Latour's 'fibrous, thread-like, wiry, stringy, ropy, capillar[ies]' and the passage of 'things' along them, research is needed to trace the people and things that make their way into children's space:

'the locales of childhood [should be understood] not as 'containers' but as places constructed through flows of heterogeneous materials. Schools, for example, are related to other schools, to households, playgrounds, after-school clubs, firms, local authorities, trades unions, ministries, courts and so on. People cross these boundaries bringing with them different and conflicting ideas, experiences, ideals, values and visions (all the things that make up discourses) and different material resources. Things also pass across the boundaries and play no less a part. These include texts, such as the curriculum guidelines, teaching materials, letters laying down funding policy and so on; and machines (such as computers) that work in this way rather than that, or facilitate that rather than this possibility for learning and so on' (Prout 2005:82)

In tracing such flows or connections, it is necessary to look outside the porous boundaries of the locales of childhood: to do otherwise is just as limiting as the historical reluctance to look inside what were once regarded as 'black boxes'. We should follow the 'capillaries' away from children themselves (in both time and space), to empirically investigate flows that are not directly visible to children (though some might be explored by them), into spaces from which children are physically absent. Policies are made and events take place beyond children's perceptions, that they cannot 
comment on, yet profoundly shape their lives. The political spaces from which children are physically absent are as important as those in which they are present.

Rather than think in global/local - structure/agency terms, Kirby (2002) suggests an alternative metaphor, derived from computing, of front regions and back regions. The front region is visible, and ordinary users engage with it relatively directly; the back region is the not-made-visible and is harder for a non-expert to access. This strongly echoes Goffman's (1959) notion of 'front stage' and 'back stage', and could be helpful in directing attention both to that which children can comment on and that which needs to be explored through other means.

It is necessary then, for research to take leave of physical, embodied children - to recognise that children can only tell us so much, that what they tell and, especially, what they tell of what they see, gives access to only a very small part of their lives. While, as researchers, our understanding cannot be complete, limiting ourselves to children-centred research restricts our perspective to a subset of children's viewpoints on their own lives. Besides researching with children, we need to research with those who are actively involved in constructing the policies and discourses that affect children, while recognising that these individuals, too, have limited knowledge and limited perceptual fields. We need to explore how childhood is (or is not) incorporated into the many happenings that impact on children's lives.

It is also important to recognise where scope lies for transforming children's worlds. Children, particularly young children, have only limited capacities to act purposefully beyond their immediate encounters with people and places. These capacities are more constrained than those of most adults. Research embedded within the NSSC that has sought to transform children's lives has generally advocated a participatory approach. Participatory methods are, however, commonly criticised for ignoring policies and practices that cannot be addressed at a local level, thereby denying the wider politics of the situation they seek to redress (Mohan 1999). While Hart (1992) argues, that participation in projects enables children to develop skills of critical reflection and comparison of perspectives needed for full political engagement, this is premised on the idea that children grow into liberal subjecthood. Furthermore, there is too often a 'tendency to confine children's activism to certain acceptable places (parks and playground design); to discount the 'political child' who speaks out against war, injustice or environmental degradation as naïve, or idealistic' (Ruddick 2007:5I6). Any 
real political change is unlikely to be achieved in the spaces conceded for children's participation. Change is needed for children now, in spaces and in policy areas that do not, and perhaps cannot, directly admit children's voices. Securing such change requires that children be understood, not as individualised subjects, but in relational terms, recognising that children's lives are produced through interaction with others (Hopkins and Pain 2007).

\section{VI: Concluding comments: children's geographies and scale}

Considering children's geographies in relation to scale highlights some aspects of children's lives that have been relatively neglected by geographers. The emphasis on the local (and its coupling with agency and concrete) has dominated research in the sub-discipline, especially in the UK. Whereas political geographers may advocate 'scale jumping' for adults constructed as local, this is not a meaningful solution for children. Other means are therefore needed, both to conceptualise children's relationship to influences from elsewhere, and to achieve meaningful positive change in children's lives across the world.

I have suggested that this might be achieved by adopting a materialist approach, drawing on notions of flat ontology and embodied subjectivity. While prompted by distinctive features of childhood, this approach has relevance not only to children. While Ruddick (2007) proposes that the child is the limit to neoliberal subjecthood, children also pose an ontological challenge in relation to scale. Theorists of scale might consider not just the scale of the body, but how humans interact with the world in physical, embodied ways, taking seriously Howitt's (2002:304) suggestion that 'the links between spatial organisation and spatial experience in vision, movement, relationship, distance and action need to be explored'. Children's knowledge of the world and capacity to act purposefully upon it have been shown to be conditioned by distance, which in turn is produced through both biophysical and social processes. Thus while is might be possible, and even helpful, to relinquish the hierarchical vocabulary of scale, materiality imposes a qualitative distinction between relations of near and far.

\section{References}

Aitken S, Lopez Estrada S, Jennings J and Aguirre L M 2006 'Reproducing life and labor: global processes and working children in Tijuana, Mexico' Childhood I3(3), 365-387

Aitken S C 200 la Geographies of young people: the morally contested spaces of identity Routledge, London 
Aitken S C 200 Ib 'Global crises of childhood: rights, justice and the unchildlike child' Area 33(2), II9127

Aitken S C 2004 'Placing children at the heart of globalization' in Janelle D G, Warf B and Hansen K (eds) WorldMinds: geographical perspectives on 100 problems Kluwer, Dordrecht, Pp. 579-583

Aitken S C and Herman T 1997 'Gender, power and crib geography: transitional spaces' Gender, Place and Culture 4(I), 63-88

Ansell N 2005 Children, youth and development Routledge, London

Ansell $\mathrm{N}$ and van Blerk L 2005 "Where we stayed was very bad ...': migrant children's perspectives on life in informal rented accommodation in two southern African cities' Environment and Planning A 37(3), 423-440

Aries P 1962 Centuries of childhood Vintage Press, New York

Asquith S 2006 'Theory, practice and research: a rationale for primary geography and overview of recent developments' in Cooper H, Rowley C and Asquith S (eds) Geography 3-I I: a guide for teachers Fulton

Bailey A R, Harvey D C and Brace C 2007 'Disciplining youthful methodist bodies in nineteenthcentury Cornwall' Annals of the Association of American Geographers 97( I), I42-I 57

Beazley H 2000 'Street boys in Yogyakarta: social and spatial exclusion in the public spaces of the city' in Bridge $G$ and Watson S (eds) A companion to the city Blackwell, London, Pp. 472-488

Bingley A 2003 'In here and out there: sensations between Self and landscape' Social and Cultural Geography 4(3), 329-345

Blaut J and Stea D 1974 'Mapping at the age of three' Journal of Geography 73, 5-9

Blunt A 1999 'Imperial geographies of home: British domesticity in India, I886-1925' Transactions of the Institute of British Geographers 24(4), 42I-440

Boyer K 2006 'Reform and resistance: a consideration of space, scale and strategy in legal challenges to welfare reform' Antipode, 22-40

Brenner N 200l 'The limits to scale? Methodological reflections on scalar structuration' Progress in Human Geography 25(4), 59I-6I4

Bunge W 1977 'The point of reproduction: a second front' Antipode 9(2), 60-76

Bunkse E V 2007 'Feeling is believing, or landscape as a way of being in the world' Geografiska Annaler B 89(3), 219-231

Cahill C 2004 'Defying gravity? Raising consciousness through collective research' Chidren's Geographies 2(2), 273-286 
Cahill C and Hart R A 2006 'Pushing the boundaries: critical international perspectives on child and youth participation - series introduction' Children, Youth and Environments I6(2), i-iii

Collinge C 2005 'The differance between society and space: nested scales and the returns of spatial fetishism' Environment and Planning D: Society and Space 23, 189-206

Colls R 2007 'Materialising bodily matter:ilntra-action and the embodiment of 'Fat" Geoforum 38(2), 353-365

Cox K R 1998a 'Representation and power in the politics of scale' Political Geography I7( I), 4I-44

Cox K R 1998b 'Spaces of dependence, spaces of engagement and the politics of scale, or: looking for local politics' Political Geography I7(1), I-23

Crewe $L$ and Collins P 2006 'Commodifying children: fashion, space, and the production of the profitable child' Environment and Planning A 38(I), 7-24

Dobson J and Stillwell J 2000 'Changing home, changing school: Towards a research agenda on child migration' Area 32(4), 395-40I

Evans B 2004 "Be fit not fat': broadening the childhood obesity debate beyond dualisms' Chidren's Geographies 2(2), 287-295

Featherstone D 2003 'Spatialities of transnational resistance to globalization: the maps of grievance of the Inter-Continental Caravan' Transactions of the Institute of British Geographers 28, 404-42 I

Gagen E 2000 'An example to us all: child developmentand identity construction in early twentieth century playgrounds' Environment and Planning A 32, 599-616

Gagen E A 2004 'Making America flesh: physicality and nationhood in early twentieth-century physical education reform' Cultural Geographies II(4), 4I7-442

Gallacher L 2005 "The terrible twos': gaining control in the nursery?' Children's Geographies 3(2), $243-$ 264

Gibson-Graham J K 2002 'Beyond global vs. local: economic politics outside the binary frame' in Herod A and Wright MW (eds) Geographies of power: placing scale Blackwell, Oxford, pp. 2560

Goffman E 1959 The presentation of self in everyday life Doubleday, New York

Gough K V and Franch M 2005 'Spaces of the street: socio-spatial mobility and exclusion of youth in Recife' Chidren's Geographies 3(2), 149 - 166

Grosz E 1994 Volatile bodies: towards a corporeal feminism Indiana University Press, Bloomington Harker C 2005 'Playing and affective time-spaces' Chidren's Geographies 3(I), 47 - 62 
Harrison P 2000 'Making sense: embodiment and the sensibilities of the everyday' Environment and Planning D: Society and Space 18, 497-517

Hart R 1979 Children's experience of place Irvington, New York

Hart R 1992 Children's participation: from tokenism to citizenship, Innocenti Essay no. 4, UNICEF, Florence, Italy

Hart R 1997 Children's participation: the theory and practice of involving young citizens in community development and environmental care Earthscan, London

Harvey D 1993 'Class relations, social justice and the politics of difference' in Squires J (ed) Principled positions: postmodernism and the rediscovery of value Lawrence and Wishart, London, PP. 85-I20

Herod A and Wright M W 2002 'Placing scale: an introduction' in Herod A and Wright M W (eds) Geographies of power: placing scale Blackwell, Oxford, pp. I-I4

Hoefle S W 2006 'Eliminating scale and killing the goose that laid the golden egg' Transactions of the Institute of British Geographers 31, 238-246

Holloway S L 1998 'Local childcare cultures: moral geographies of mothering and the social organization of pre-school children' Gender, Place and Culture 5(I), 29-53

Holloway S L and Valentine G 2000a 'Children's geographies and the new social studies of childhood' in Holloway S L and Valentine G (eds) Children's geographies: playing, living, learning Routledge, London, Pp. I-26

Holloway S L and Valentine G 2000b 'Spatiality and the new social studies of childhood' Sociology 34(4), 763-783

Holt L 2004 'Children with mind-body differences: performing disability in primary school classrooms' Children's Geographies 2(2), 219 - 236

Holt L 2006 'Exploring 'other' childhoods through quantitative secondary analyses of large scale surveys: opportunities and challenges for children's geographies' Chidren's Geographies 4(2), |43-156

Holt L and Holloway S L 2006 'Editorial: Theorising other childhoods in a globalised world' Children's Geographies 4(2), I35-142

Hopkins P and Pain R 2007 'Geographies of age: thinking relationally' Area 39(3), 287-294

Horschelmann K and Schafer N 2005 'Performing the global through the local: globalisation and individualisation in the spatial practices of young East Germans' Children's Geographies 3(2), $219-242$ 
Horton J and Kraftl P 2006a 'Not just growing up, but going on: materials, spacings, bodies, situations' Chidren's Geographies 4(3), 259 - 276

Horton J and Kraftl P 2006b 'What else? Some more ways of thinking and doing 'children's geographies" Children's Geographies 4(I), 69-95

Howitt R 2002 'Scale and the other: Levinas and geography' Geoforum 33, 299-3 I 3

James A, Jenks C and Prout A 1998 Theorising childhood Teachers College Press, New York

Jennings J, Aitken S, Lopez Estrada S and Fernandez A 2006 'Learning and earning: relational scales of children's work' Area 38(3), 23I-239

Jonas A E G 2006 'Pro scale: further reflections on the 'scale debate' in human geography' Transactions of the Institute of British Geographers 31, 399-406

Jones J P I, Woodward K and Marston S A 2007 'Situating flatness' Transactions of the Institute of British Geographers 32(2), 264-276

Jones K T 1998 'Scale as epistemology' Political Geography I7( I), 25-28

Jones O 1999 'Tomboy tales: the rural, nature and the gender of childhood' Gender, Place and Culture $6(2), 117-136$

Jones O 2005 'An emotional ecology of memory, self and landscape' in Davidson J, Bondi L and Smith M (eds) Emotional geographies Ashgate, Oxford

Katz C 199I 'Sow what you know: the struggle for social reproduction in rural Sudan' Annals of the Association of American Geographers 8I(3), 488-5I4

Katz C 1993 'Growing girls/closing circles: limits on the spaces of knowing in rural Sudan and United States cities' in Katz C and Monk J (eds) Full circles: geographies of women over the life course Routledge, London

Katz C 1994 'Textures of global changes: eroding ecologies of childhood in New York and Sudan' Childhood 2, 103-110

Katz C 1998 'Disintegrating developments: global economic restructuring and the eroding of ecologies of youth' in Skelton T and Valentine G (eds) Cool places: geographies of youth cultures Routledge, London

Katz C 200I 'Vagabond capitalism and the necessity of social reproduction' Antipode 33(4), 708-727

Katz C 2004 Growing up global: economic restructuring and children's everyday lives University of Minnesota Press, Minneapolis

Kesby M, Gwanzura-Ottemoller F and Chizororo M 2006 'Thorising other, 'other childhoods': issues emerging from work on HIV in urban and rural Zimbabwe' Chidren's Geographies 4(2), I85-202 
Kirby A 2002 'Popular culture, academic discourse, and the incongruities of scale' in Herod A and Wright M W (eds) Geographies of power: placing scale Blackwell, Oxford, Pp. I7I-I9|

Latham A 2002 'Retheorizing the scale of globalization: topologies, actor-networks, and cosmopolitanism' in Herod A and Wright MW (eds) Geographies of power: placing scale Blackwell, Oxford, Pp. II5-I44

Latour B 2005 Reassembling the social: an introduction to actor-network-theory Oxford University Press, Oxford

Mahon R 2006 'Of scalar hierarchies and welfare redesign: child care in three Canadian cities' Transactions of the Institute of British Geographers 31, 452-466

Marston S A 2000 'The social construction of scale' Progress in Human Geography 24(2), 21 9-242

Marston S A, Jones J P I and Woodward K 2005 'Human geography without scale' Transactions of the Institute of British Geography 30, 4I6-432

Massey D 1993 'Politics and space/time' in Keith M and Pile S (eds) Place and the politics of identity Routledge, London, Pp. |41-161

Massey D 1998 'The spatial construction of youth cultures' in Skelton T and Valentine G (eds) Cool places: geographies of youth cultures Routledge, London

Massey D 2005 For space Sage, London

Matthews H 2005 'Editorial: rising four: reflections on the state of growing-up' Children's Geographies $3(3), 27 I-273$

Matthews H and Limb M 1999 'Defining an agenda for the geography of children: review and prospect' Progress in Human Geography 23(I), 61-90

Matthews H, Limb M and Percy-Smith B 1998 'Changing worlds: the microgeographies of young teenagers' Tijdschrift voor Economische en Sociale Geografie 89(2), 193-202

Matthews H, Limb M and Taylor M 1999 'Young people's participation and representation in society' Geoforum 30, I35-144

McCarthy J 2005 'Scale, sovereignty, and strategy in environmental governance' Antipode, 73 I-753

McKendrick J H, Bradford M G and Fielder A V 2000 'Kid customer? Commercialization of playspace and the commodification of childhood' Childhood 7(3), 295-3। 4

McNeish D and Gill T 2006 'Editorial: UK policy on children: key themes and implications' Children's Geographies 4(I), I-7

Miettinen R 2000 'The riddle of things: activity theory and actor-network theory as approaches to studying innovations' Mind, Culture and Activity 6(3), 170-195 
Mitchell K 2003 'Educating the national citizen in neoliberal times: from the multicultural self to the strategic cosmopolitan' Transactions of the Institute of British Geographers 28(4), 387-403

Mohan G 1999 'Not so distant, not so strange: the personal and the political in participatory research' Ethics, Place and Environment 2(I), 4I-54

North P 2005 'Scaling alternative economic practices? Some lessons from alternative currencies' Transactions of the Institute of British Geographers 30, 221-233

O'Toole T 2003 'Engaging with young people's conceptions of the political' Children's Geographies I(I), $71-90$

Paasi A 2004 'Place and region: looking through the prism of scale' Progress in Human Geography 28(4), 536-546

Pain R 2004 'Introduction: children at risk?' Children's Geographies 2(1), 65-67

Pain R 2006 'Paranoid parenting? Rematerializing risk and fear for children' Social and Cultural Geography 7(2), 221-243

Philo C 2000 "The corner-stones of my world': editorial introduction to special issue on spaces of childhood' Childhood 7(3), 243-256

Philo C 2003 "To go back up the side hill': memories, imaginations and reveries of childhood' Children's Geographies I(I), 7-23

Piaget J 1972 The principles of genetic epistemology Routledge and Kegan Paul, London

Prout A 2005 The future of childhood RoutledgeFalmer, Abingdon

Punch S 2007 'Negotiating migrant identities: young people in Bolivia and Argentina' Chidren's Geographies 5(1-2), 95-1 12

Qvortrup J 2005 'Varieties of childhood' in Qvortrup J (ed) Studies in modern childhood: society, agency, culture Palgrave Macmillan, Pp. I-20

Roberts S M 1998 'What about the children?' Environment and Planning A 30, 3-I I

Robson E 1996 'Working girls and boys: children's contributions to household survival in West Africa' Geography 8I(4), 403-407

Robson E 2000 'Invisible carers: young people in Zimbabwe's home-based healthcare' Area 32(I), 5970

Robson E 2004 'Hidden child workers: young carers in Zimbabwe' Antipode 36(2), 227-248

Ruddick S 2003 'The politics of aging: globalization and the restructuring of youth and childhood' Antipode 35(2), 334-362 
Ruddick S 2007 'At the horizons of the subject: neo-liberalism, neo-conservatism and the rights of the child. Part One: From 'knowing' fetus to 'confused' child' Gender, Place and Culture I4(5), 5 I3526

Schatzki T 2002 The site of the social: a philosophical account of the constitution of social life and change Pennsylvania State University Press, Pennsylvania

Schwanen T 2007 'Matter(s) of interest: artefacts, spacing and timing' Geografiska Annaler B 89(I), 9-22 Skelton T 2000 "Nothing to do, nowhere to go?': teenage girls and 'public' space in the Rhondda Valleys, South Wales' in Holloway S L and Valentine G (eds) Children's geographies: playing, living, learning Routledge, London

Smith F 2004 'Is there a place for children's geographers in the policy arena' Children's Geographies 2(I), |57-|6I

Sporton D, Valentine G and Nielsen K B 2006 'Post conflict identities: affiliations and practices of Somali asylum seeker children' Children's Geographies 4(2), 203-2 I8

Swyngedouw E 1997 'Neither global nor local: 'glocalisation' and the politics of scale' in Cox K (ed) Spaces of globalisation: reasserting the power of the local Guilford, London, Pp. 137-166

Tatek Abebe 2007 'Changing livelihoods, changing childhoods: patterns of children's work in rural southern Ethiopia' Chidren's Geographies 5(I-2), 77-94

Taylor P J 1982 'A materialist framework for political geography' Transactions of the Institute of British Geographers 7, 15-34

Thomson S 2005 "Territorialising' the primary school playground: deconstructing the geography of playtime' Chidren's Geographies 3(I), 63 - 78

Tillberg Mattsson K 2002 'Children's (in)dependent mobility and parents' chauffeuring in the town and the countryside' Tijdschrift voor Economische en Sociale Geografie 93(4), 443-453

Valentine G 1997a "'Oh yes I can." "Oh no you can't": Children and parents' understandings of kids' competence to negotiate public space safely' Antipode 29(I), 65

Valentine G 1997b 'A safe place to grow up? Parenting, perceptions of children's safety and the rural idyll' Journal of Rural Studies I3(2), I37-I48

Valentine G 2000 'Exploring children and young people's narratives of identity' Geoforum 3I(2), 257267

van Blerk L and Ansell N 2006a 'Children's experiences of migration in Southern Africa: moving in the wake of AIDS' Environment and Planning D 
van Blerk L and Ansell N 2006b 'Imagining migration: the impact of place on children's understanding of 'moving house' in Southern Africa' Geoforum 37(2), 256-272

van Blerk L and Ansell N 2007 'Participatory feedback and dissemination with and for children: reflections from research with young migrants in southern Africa' Chidren's Geographies 5(3), $313-324$

Vygotsky L S 1933/I967 'Play and its role in the mental development of the child' Soviet Psychology $5(3), 6-18$

Ward C 1978 The child in the city Pantheon, New York

Wood D and Beck R J 1994 Home rules Johns Hopkins University Press, Baltimore

Young L 2004a 'Journeys to the street: the complex migration geographies of Ugandan street children' Geoforum 35(4), 47I-488

Young L 2004b 'The 'place' of street children in Kampala, Uganda: marginalisation, resistance and acceptance in the urban environment' Environment and Planning D: Society and Space 2I, 607627 